\title{
ACONTECIMIENTO Y VERDAD HISTÓRICA. UNA LECTURA DESDE LA PERSPECTIVA RICOEURIANA
}

\section{Cristina Micieli ${ }^{*}$}

\section{El acontecimiento eclipsado y el eclipse del acontecimiento ${ }^{1}$}

Ricoeur elabora un pensamiento sobre la bistoria que muestra que tras el análisis de los grandes períodos o de legalidades históricas, queda oscurecida la noción de acontecimiento.

Es necesario potenciar el pensamiento, y éste no es un mero conocimiento, nos dice Ricoeur. Un pensamiento es el lugar en donde es posible que se produzcan las verdades de una época ${ }^{2}$.

Toda situación se constituye por una operación que consiste en suturar y eliminar su punto de inconsistencia, su vacío. Pero para tomar noticia de esta inconsistencia, que nos alerta que es posible otra cosa que la que marca la unidad de los conocimientos que la forman, es necesaria la irrupción, sin duda azarosa, de un exceso que haga fracasar a los conocimientos constituidos y obligue a construir una nueva verdad de la situación, una nueva manera de comprenderla.

Este exceso es el acontecimiento, ya que éste aun formando parte de la situación no puede ser explicado por los recursos (conocimientos vigentes) de la misma. Y si el viejo conocimiento es impotente para pensar el acontecimiento, obliga, por ende, a pensar más allá de sus límites. Esto significa toparse con lo impensable de esa situación.

* Profesora e investigadora en la Facultad de Ciencias Sociales de la UBA. cmicieli@educ.ar

1 Ricoeur habla de un eclipse del acontecimiento en la historiografía francesa. Cfr. Tiempo y narración, traducción de Agustín Neira, Vol. I, Siglo XXI, Madrid, 1999, p. 171 y ss.

${ }^{2}$ Cfr. Ricoeur, Paul, Tiempo y narración, Vol. III, ob.cit., p. 839. 
Ricoeur utiliza la palabra "ruptura" para referirse a la irrupción del acontecimiento, pues con ello se da cuenta de una falla que resquebraja desde el interior la presunta idea englobadora y totalizante de la historia del mundo, pudiéndose seguir por la huella los efectos devastadores de esta falla ${ }^{3}$. El alcance de un acontecimiento expresa la persistencia de sus efectos lejos de la fuente.

Asimismo, no existe acontecimiento que pueda escapar a la narrativización, y es a través de ella que éste puede ser integrado a la estructura y a la coyuntura. La trama en tanto síntesis de lo heterogéneo puede integrar lo que la epistemología de la historia disocia. Como vemos, la unión de trama-acontecimiento es transportada al plano historiográfico por Ricoeur. Siguiendo la Poética de Aristóteles, Ricoeur llama súbitos a aquellos acontecimientos que suscitan un viraje inesperado "contra toda previsión". En términos generales, toda discordancia que rivaliza con la concordancia de la acción es equivalente al acontecimiento en sentido aristotélico. Pero junto a los acontecimientos repentinos, súbitos, breves, hallamos también los de larga duración, por la extensión y el alcance de la historia narrada, como el Renacimiento, la Reforma, la Revolución Francesa, todos ellos acontecimientos en relación a una trama multisecular ${ }^{4}$.

Por otra parte, no es a través de la categoría de verdad que las verdades son producidas; éstas se producen por mecanismos singulares que ocurren después de los acontecimientos. Las verdades van de la mano del pensamiento y lo verdadero comulga con el conocimiento. La potencia de las verdades abre el camino de nuevas configuraciones en el conocimiento. Esto quiere decir que todo conocimiento real, instituido, plasmado, reconoce como punto de partida de su posibilidad una ruptura, un "imposible". No obstante, este nuevo conocimiento que logra instituirse, por más coherente y totalizador que se muestre, nunca podrá abolir ese azar, esa contingencia que está en la "matriz" de todo conocimiento. De allí la necesidad de desfatalizar el pasado a fin de poner de relieve que los

3 Ricoeur, Paul, La memoria, la bistoria, el olvido, traducción de Agustín Neira, FCE, México, 2004, p. 394.

4 Ibidem, pp. 317-318. 
hombres del pasado han sido sujetos de iniciativa en un presente viviente como el nuestro. Es posible, así, concebir los acontecimientos de otro modo, con lo cual se está empleando un recurso terapéutico que puede curar la memoria hérida. En efecto, permite una terapia respecto de las patologías en la conciencia histórica. En fin, el conocimiento establecerá lo verdadero pero nunca encarcelará las verdades. Por lo tanto, no hay conocimiento de la verdad sino producción de verdades.

Hemos heredado el problema de la totalidad de Hegel, afirma Ricoeur, pero no es posible resolverlo equiparando la serie de etapas de desarrollo histórico con el presente eterno de la razón. Esta pérdida de alteridad del pasado es incompatible con las nociones de representancia y buella, de ahí que Ricoeur rechace la ambición del pensamiento de operar una totalización de la historia.

Bajo la denominación de pensamiento de la historia, que se diferencia tanto de la filosofía especulativa como de la epistemología, Ricoeur explicita las aporías que enfrenta el historiador, ante la imposibilidad de mediar entre el tiempo vivido y el tiempo cósmico.

Asimismo, el historiador pasa por alto la intención ontológica que anima su tarea, porque se limita al valor gnoseológico que tiene el documento en tanto prueba, omitiendo, de esta forma, el problema implicado en la noción de huella, en tanto enigma de la referencia histórica. De ahí que Ricoeur prefiera hablar de representancia y no de referencia o representación.

La fenomenología de la memoria ${ }^{5}$ nos ha enseñado que la frontera entre realidad y ficción se vuelve problemática. $\mathrm{Y}^{*}$ este

${ }^{5}$ Ricoeur procura hacer una fenomenología de la memoria basada en una conquista de la distancia temporal. Se refiere a un gradiente de distanciación que va desde la memoria/hábito, en el que el pasado es inmanente al presente y no se distingue de él, hasta el recuerdo del pasado lejano. Procura contrarrestar tanto el exceso de la memoria que exagera el primer aspecto, como el olvido de la misma que exageta el segundo. 
carácter problemático "no dejará de atormentarnos, dice Ricoeur, hasta la fase de la representación histórica del pasado"6.

Representación es una noción polisémica. Por un lado, la representación es el modo hegemónico del pensamiento que acompaña el advenimiento de la modernidad, en donde el sujeto de la conciencia -que en definitiva siempre es autoconciencia- se vuelve sustancia fundante. Este radical cambio de posición subjetiva posibilita la producción de dispositivos del tipo "imagen del mundo".7 La representación "designaría, afirma Ricoeur, los múltiples trayectos del trabajo de reconocimiento de cada uno a cada uno y de cada uno a todos; se asemejaría, entonces, a la noción de 'visión del mundo'..." 8 .

La idea de representación tiene una estructura bipolar: por una parte, evoca la cosa ausente por mediación de otra que la sustituye y que la representa por defecto; por otra, el representante puede ocultar la operación de sustitución, apareciendo como una presencia plena 9 .

No obstante, la esencia de la representación consiste en construir esa presencia a partir precisamente de lo que la representación dice de ella, desnudando, de esta manera, el juego especular del mecanismo de la representación. Si no existiera ninguna presencia para ser representada, ésta naufragaría; en consecuencia, debemos presuponer esa presencia, la cual, finalmente, no es sino aquello que la misma representación define y enmarca.

Sin embargo, el acontecimiento debe ser "representado" en su figura de eclipse; el acontecimiento surge, pero tal emergencia es al mismo tiempo su desvanecimiento. Lo que subsistirá del acontecimiento es su nombre. Lo que circulará a partir de entonces no será el acontecimiento como tal que se ha evanecido y rescindido, sino su nominación. La nominación del acontecimiento, entonces, es lo que circulará en el futuro.

6 Ricoeur, Paul, La memoria, la bistoria, el olvido, ob.cit., p. 211.

7 Véase Heidegger, M., "La época de la imagen del mundo", en Caminos del bosque, trad. de Helena Cortés y Arturo Leyte, Alianza, Madrid, 2000, p. 77.

${ }^{8}$ Ricoeur, Paul, La memoria, la bistoria, el olvido, ob.cit., p. 300.

9 Ibidem, p. 301. 
$\mathrm{Al}$ respecto, Ricoeur se refiere, entre otros, al uso del nombre propio "Revolución Francesa" en tanto signo distintivo de una lógica circular, en virtud de la cual el nombre propio funciona como sujeto lógico para toda la serie de atributos que lo desarrollan. Estas narratio -término atribuido a F. R. Ankersmit- tienden a la autorreferencialidad, en la medida en que el sentido del nombre propio no se da en ningún otro lugar, sólo en esta serie de atributos.

Así, el nombre propio se impone sobre la controversia abierta entre historias o interpretaciones rivales (la de Michelet, o la de Furet, o la de Mathiez, en el ejemplo citado) ${ }^{10}$. En la representación, acontecimiento y nombre van juntos, afirma Ricoeur ${ }^{11}$.

\section{La "impresentación" de la huella}

El concepto ricoeuriano de representancia, desde mi punto de vista, supera el dispositivo presentación/representación, en la medida en que le da toda su potencia a lo que se substrae a la presentación.

Por su parte, que el pasado haya dejado una huella, es el presupuesto para que los documentos puedan ser coleccionados en archivos. La huella se hace visible aquí, en el espacio, y ahora, en el tiempo presente, a la manera de un testigo o de una marca; hay huella porque con anterioridad algo ha sucedido. Es su vestigio. Pero la particularidad de la huella radica en que su testimonio o marca indica sin mostrar, sin hacer aparecer. En la huella se preserva un pasado perimido, sin embargo éste no se muestra como una idea "clara y distinta", sino más bien, en tanto marca "confusa, oscura y ambigua".

Ricoeur nos enseña que la historiografía es conocimiento por huellas, de allí que el papel jugado por la imaginación sea clave. En efecto, le atribuimos a la huella valor porque nos figuramos el mundo de la vida que hoy falta. La huella es una presencia ausente.

${ }^{10}$ Cfr. Ricoeur, Paul, La memoria, la bistoria, el olvido, ob.cit., pp. 363-364. Sobre ello recae una "sospecha de cierre" que se levanta entre el significante/significado y el referente.

11 Para Ricoeur este proceso de nominación resulta inquietante en el caso de los “relatos fundadores". Cf. Idem., p. 445. 
Es necesario seguir la huella, remontarla e interpretarla como signo, porque ella es efecto de una causa y signo de un sentido. Se trata de avanzar, en consecuencia, desde la impronta dejada aquí y ahora hacia el acontecimiento.

Por la materialidad de la marca dejada, la huella suscita inferencias de tipo causal, y éstas se relacionan con la inscripción del pasado en el tiempo del universo. La inferencia, en definitiva, se relaciona con la exterioridad del pasado.

La huella tiene que ver con la inscripción en el tiempo del universo, ya que la noción de fecha se asocia con el calendario, implicando la remisión a una perspectiva cósmica sobre el tiempo. En este sentido, se trata de un tiempo que está sometido a cálculo y medida, y al remontar la huella desciframos la extensión del mismo. La huella, en consecuencia, remite a una perspectiva cósmica sobre el tiempo.

Pero, por otro lado, la huella nos lleva a un mundo ausente, suscitando la interpretación de su carácter significativo. Así, la huella se asocia con una preocupación pasada y con el tiempo vivido de esta preocupación.

En este sentido, la huella es un conector entre el tiempo público o cósmico y el tiempo fenomenológico, ya que establece un intercambio entre ambos. La huella, entonces, designa la exterioridad del pasado, la inscripción del pasado en el tiempo del universo.

El análisis de la huella se relaciona con el de la representancia, pues la huella significa sin mostrar, es un ver como, característico de la representancia. El ver como contribuye parcialmente a una solución del problema inherente a la huella, en tanto ella es aquello que vale por el pasado. El ver como tiene su correlato en un ser como, y éste es, a su vez, ser y no ser. En efecto, Ricoeur relaciona el "tal como" de la fórmula de Ranke, "tal como ocurrió realmente", con el análisis del "como" en el capítulo final de La metáfora viva, donde une el "ver-como" del plano semántico con el "ser-como" del plano ontológico. Así se hace posible hablar de la "redescripción metafórica" del pasado mediante la historia. 
Según la interpretación analógica de lugartenencia y representancia, ésta tiene la fuerza de la reefectuación y del distanciamiento. En este sentido, el análisis de la representancia añade la distancia temporal a la inscripción del tiempo fenomenológico en el cósmico.

$\mathrm{El}$ análisis de la huella tiene que ser completado por el de la tradición como aquello que nos afecta. Precisamente la tradición es la que fluye subterráneamente, por así decirlo, debajo del acontecimiento, dándole a éste, luego de pasado el momento de su irrupción, un nuevo sentido. Ricoeur señala que la transmisión de los contenidos de las tradiciones tiene ante todo una estructura lingüística, por eso entendemos por tradición las cosas ya dichas en tanto nos son transmitidas a lo largo de la cadena de interpretación y re-interpretación.

Por su parte la tradicionalidad implica para Ricoeur una dialéctica de distanciamiento, por un lado, y de des-distanciamiento, por otro. Y esto se contrapone por igual a la idea de una distancia infranqueable, como también a la idea de una distancia anulada en nuestra relación con el pasado histórico. De manera que se descarta un pasado perimido y abolido, como también la contemporaneidad integral del pasado.

La noción de tradicionalidad implica que la distancia temporal que nos separa del pasado no es un intervalo muerto, sino que la mediación entre pasado y futuro es una transmisión generadora de sentido.

El análisis de Ricoeur se desenvuelve en tres planos: el de huella en tanto significa sin hacer aparecer; el de la representancia interpretada como un ver como $\mathrm{y}$, por lo tanto, apunta a un ver histórico; y el plano de la conciencia expuesta a la eficacia de la historia. Podemos hacer la historia en tanto somos afectados por el pasado. Sólo en este último plano, en relación con la historia por hacer, con el horizonte de espera, se adquiere plena conciencia de la realidad del pasado histórico. 


\section{Conclusiones}

Hacer la historia, en el sentido de narrar críticamente, equivale a hacer la historia en tanto proyección de un futuro. Somos fieles a la memoria en la medida en que a través de la producción de verdad de la historia crítica, descubrimos nuevas posibilidades en el pasado.

La pretensión de verdad de la historia adquiere sentido con relación a la pretensión de verdad de las ciencias humanas y las de la naturaleza. Pero el "reto referencial", afirma Ricoeur, de esta pretensión es en el caso de la historia el pasado mismo. Y en este punto ya no es posible definir este reto referencial a través de los términos "correspondencia" o "adecuación"12. Asimismo, no es posible llamar "real" al momento de la aserción de la representación, ya que nunca el relato de un acontecimiento "es" el acontecimiento. De allí la necesidad de una historia crítica que tiene que luchar no sólo contra los prejuicios de la memoria colectiva, sino también contra los de la historia oficial (historia colectiva oficializada).

Hay una dialéctica entre historia y memoria crítica, y el recurso a la investigación, a la explicación y a la escritura le permite a la historiografía relatar de otro modo y pasar por el relato de los otros acreditando, de este modo, la pretensión de verdad del discurso histórico ${ }^{13}$.

Como dijimos, en tanto fundada sólo en una identidad, la representación produce efectos de congelamiento. Enmarca y asienta una situación dada respecto a los individuos comprometidos en ella. Es una fuente de reconocimientos mutuos en relación a los implicados. Mediadora y niveladora por excelencia, conecta las multiplicidades y oposiciones más diversas hasta depositarlas en un suelo común en el que aquellas se reflejan y comunican como formando diversas instancias de lo mismo. Precisamente para dar cuenta del enigma de la referencia histórica, Ricoeur recurre a una dialéctica de tres grandes géneros, según infiere de $E$ l sofista de Platón: la dialéctica de lo mismo, lo otro y lo análogo. O en otras palabras,

${ }^{12}$ Ricoeur, Paul, La memoria, la bistoria, el olvido, ob.cit., pp. 366-367.

${ }^{13}$ Cfr., Ibidem., p. 365. 
decimos algo con sentido respecto del pasado cuando lo pensamos sucesivamente bajo el signo de lo mismo, lo otro y lo análogo. Asimismo, cada uno de estos tres momentos tiene su representante o su representación en la historia del pensamiento, sin embargo, cada uno unilateralmente no puede resolver el problema del enigma de lo que Ricoeur va a llamar representancia o lugartenencia. En efecto, esta dialéctica debe problematizar el carácter de realidad aplicado al pasado, ya que entre el relato histórico y los acontecimientos pasados no hay una relación de reproducción o reduplicación. El concepto de representancia se diferencia del de representación porque la referencia al pasado es metafórica. Y esta metáfora se caracteriza por un ver como que tiene su correlato en un ser como. Esta es a la vez un ser y un no-ser.

A diferencia de la ficción, la construcción del historiador es una re-construcción del pasado. Para Ricoeur, el enigma de la referencia histórica se relaciona con la noción de huella, que encierra una cuestión ontológica. Con el concepto de representancia o lugartenencia, el filósofo intenta dar una solución al valor mimético de la huella y, más allá, al sentimiento de deuda del historiador respecto del pasado.

El acontecimiento pasado no puede ser percibido; se halla ausente. Sin embrago, no por eso deja de regir la intencionalidad histórica, confiriéndole una nota realista. En efecto, afirma Ricoeur, ninguna literatura por más realista que pretenda ser podrá sustituir el acontecimiento histórico ${ }^{14}$.

Nos dice Ricoeur: "la representación histórica es sin duda la imagen presente de la cosa ausente; pero la cosa ausente se desdobla a su vez en desaparición y existencia en el pasado. Las cosas pasadas están abolidas, pero nadie puede hacer que no hayan sido"15. Este estatuto particular del pasado es expresado por numerosas lenguas a través de un sutil juego entre tiempos verbales y adverbios de tiempo. Se dice que algo ya no es, pero fue. Parecería que "el haber sido" es el último referente buscado a través del "ya no ser". Es como si la ausencia se desdoblara: por un lado, en ausencia como objetivo de la

\footnotetext{
14 Ibidem., p. 368.

15 Ibidem.
} 
imagen presente y, por otro, en ausencia de las cosas pasadas como pasadas respecto de su "haber sido". Sólo así, afirma Ricoeur, el antes significa la realidad, pero la realidad en el pasado. En este punto, la epistemología de la historia se enfrenta con la ontología del ser-en-elmundo.

Ricoeur llama condición histórica a este régimen de "vehemencia asertiva" de la representación histórica. En cuanto representancia, ésta se apoya en la posibilidad del "haber sido" buscado a través de la negatividad del "ya no ser".

Aquí la epistemología de la operación historiográfica alcanza su límite interno al bordear los confines de la ontología del ser histórico, como dijimos ${ }^{16}$.

Pero no existe un conocimiento exacto, riguroso, objetivo. Esta mirada objetivista se sostenía en el convencimiento de que había leyes en la historia y que éstas se desenvolvían inexorablemente, pese a la existencia de recaídas. De esa manera, se empezó a dibujar la figura del historiador progresista, por un lado, y el historiador ideológico, defensor del sistema, por otro. $\mathrm{El}$ primero buscaba en las profundidades para traer a la superficie los datos fríos y desnudos de la realidad, mientras que los otros la ocultaban, trucaban o disimulaban.

Ricoeur cuestiona esta concepción, que finalmente lejos de complejizar, simplifica el acceso del historiador al acontecimiento histórico. Hay una referencia cruzada entre la historiografía y la narración de ficción, y la temporalidad es el "lugar" donde se cruzan la referencia por huellas y la metafórica.

La historia crítica interviene en la dialéctica entre espacio de experiencia y horizonte de espera para que su verdad no se separe de la fidelidad a las posibilidades no realizadas o promesas no cumplidas del pasado.

Hacer la historia, en el sentido de narrar críticamente, equivale a hacer la historia en el sentido de proyectar un futuro. Somos fieles a 
la memoria en la medida en que a través de la verdad de la historia crítica, descubrimos nuevas posibilidades en el pasado. En efecto, aunque no se pueden borrar los hechos del pasado, se puede reinterpretar el sentido de los mismos, porque éste no está fijado de una vez para siempre. Así, podemos cambiar la carga moral del pasado, o sea, la deuda que pesa sobre el presente ${ }^{17}$.

De allí que sea necesario, como ya dijimos, potenciar el pensamiento, y éste no es un mero conocimiento. Un pensamiento es el lugar en donde es posible que se produzcan las verdades de una época.

\section{Bibliografia}

Ricoeur, Paul, Tiempo y narración, traducción de Agustín Neira, Vol. I y III, Madrid, Siglo XXI, 1999.

Ricoeur, Paul, La memoria, la bistoria, el olvido, traducción de Agustín Neira, México, FCE, 2004.

\section{Resumen}

Ricoeur elabora un pensamiento sobre la bistoria que muestra que tras el análisis de los grandes períodos o de legalidades históricas, queda oscurecida la noción de acontecimiento.

Desde mi punto de vista, el acontecimiento es la irrupción, sin duda azarosa, de un exceso que hace fracasar los saberes constituidos y obliga a construir una nueva verdad de la situación, esto es, una nueva manera de entenderla.

Ricoeur habla de representancia y no de referencia o representación. Siendo la representación el modo hegemónico del pensamiento que acompaña el advenimiento de la modernidad, en donde el sujeto de la conciencia - que en definitiva siempre es autoconciencia- se vuelve sustancia fundante, el

${ }^{17} \mathrm{El}$ concepto de deuda-herencia debe situarse bajo el de representancia en el marco de la epistemología del conocimiento histórico como guardián de la pretensión referencial del discurso histórico: "que las construcciones del historiador puedan ambicionar ser tangencialmente, de alguna forma, reconstrucciones de lo que realmente pasó 'tal como efectivamente sido', según las palabras de Ranke, es lo que quiere decir el concepto de representancia". En Ricoeur, Paul, La memoria, la bistoria, el olvido, ob.cit., p. 469. 
concepto ricoeuriano de representancia, desde mi punto de vista, supera el dispositivo presentación/representación, en la medida en que le da toda su potencia a lo que se substrae a la presentación.

En efecto, entre el relato histórico y los acontecimientos pasados no hay una relación de producción o reduplicación. El concepto de representancia se diferencia del de representación porque la referencia al pasado es metafórica. $Y$ esta metáfora se caracteriza por un ver como que tiene su correlato en un ser como. Esta es la vez un sery un no-ser.

En este artículo, se vinculan los conceptos de acontecimiento, representancia, huella y verdad histórica.

Palabras clave: "Acontecimiento"; “representancia"; “representación"; "huella"; "verdad".

\section{Abstract}

Ricoeur elaborates a trend of thought about history which shows that behind the analysis of the great periods or historical legalities, the notion of event [happening]remains obscured.

From my point of view, the event is the undoubtedly haphazard irruption of an excess which causes the failure of constituted knowledge and obliges to construct a new truth of the situation, i.e., a new way of comprehending it.

Ricoeur speaks of representance, and not of reference or representation. Representation being the hegemonic mode of thought which accompanies the advent of modernity, in which the subject of conscience -which is after all always selfconscience- becomes grounding substance. From my point of view, the recoeurian concept of representance surpasses, the presentation/representation device, inasmuch as it gives all its power to what conceals itself form presentation.

In fact, there is no relation of production o reduplication between historical narration and past events. The concept of representance distinguishes itself from that of representation because the reference to past is metaphoric. And this metaphor is characterized by a seeing as which has its correlate in a being as. It is a being and not being at the same time.

In this article the concepts of event, representance trace and historical truth are bound toghether.

Key words: "Event"; "representance"; "representation"; "trace"; "truth". 